\title{
Sanar a inteligência. Contestações ensaísticas de Ernesto Palacio e Victoria Ocampo a José Ortega y Gasset
}

\author{
Leonardo D'Ávila de Oliveira
}

UFSC

\begin{abstract}
Resumo
Em seu primeiro livro, Meditaciones del Quijote, de 1914, Ortega y Gasset relaciona o pensar ensaístico a uma salvação, algo que se desdobra em seus textos subsequentes em conceitos como nueva salud e nueva sensibilidad. Este artigo evidencia como essa metáfora metalinguística vai ser discutida na Argentina no ensaio En el país del arte deshumanizado, de Ernesto Palacio, de 1928, bem como em Contestación a um epílogo de Ortega y Gasset, de Victoria Ocampo, publicado em 1931. Essas duas contestações semelhantes, porém de autores distintos, terão em comum o fato de considerar que essa nova saúde não se dá por uma nova maneira de se relacionar com o sensível, como queria o filósofo espanhol, senão enquanto esforço de sanar a inteligência. Entretanto, esses ensaios que respondem a Ortega não chegam a evitar que sua principal força esteja justamente nas imagens que manifestam, de modo que, paradoxalmente, opõem, à nueva sensibilidad, novas sensações.
\end{abstract}

Palavras-chave: ensaio; saúde; inteligível; sensível.

\begin{abstract}
In his first book, Meditaciones del Quijote, from 1914, Ortega y Gasset, thinking about essays, establishes a relation between thought and salvation, which will later be important to his concepts of nueva salud and nueva sensibilidad. This article exposes how this metalinguistic metaphor is discussed in Argentina in Ernesto Palacio's essay En el país del arte deshumanizado, published in 1928, as well as in Contestación a un epílogo de Ortega y Gasset, by Victoria Ocampo, published in 1931. These two similar contestations from very distinct authors, all have in common the fact of considering that this new health is not given by a new way of dealing with senses, as in the Spanish thinker, but in an idea of remedying intelligence. However, these essays that interpolate Ortega cannot avoid that their main strength relies exactly in the images that they manifest. And by doing so, paradoxically, they oppose new sensations to the nueva sensibilidad.
\end{abstract}

Keywords: essay; health; intelligible; sensory. 
1. “e começou: "Tu estás entorpecido / por tua imaginação, tão que não vês / o que verias se a houvesses sacudido." ALIGHIERI, Dante. A Divina Comédia - Paraíso, 1998, p. 16.

2. ORTEGA Y GASSET, José. Meditaciones del Quijote, 1914, p. 43.

3. Ibidem, p. 32.

4. Ibidem, p. 32-33.

5. Cf. ORTEGA Y GASSET, José. La deshumanización del arte. Ideas sobre la novela, 2009. e cominciò: "Tu stesso ti fai grosso col falso imaginar, si che non vedi ciò che vedresti se l'avessi scosso."

Dante $^{1}$

A abertura do ensaio Meditaciones del Quijote (1914), primeiro livro publicado de José Ortega y Gasset, traz vários apontamentos embrionários que seriam desenvolvidos em trabalhos posteriores. Entre eles, há a célebre definição de que "yo soy yo y mi circunstancia" 2 , cujo sentido seria a base de sua obra mais madura, a exemplo do que se poderá verificar em El tema de nuestro tiempo, de 1923, no qual fica saliente o imperativo de se refundar a realidade a partir de novas perspectivas, muito mais do que simplesmente ajustar-se a ela. Contudo, antes de ser uma coletânea apenas de ideias ou temas em formação, sua meditação demonstrava um interessante esforço metalinguístico a ponto de o autor colocar o gênero como sinônimo de salvação. O ensaio Meditaciones del Quijote é, para Ortega y Gasset, também um ensaio sobre o ensaiar, uma evidenciação da necessidade de se buscar o exercício constante da reflexão com liberdade e arrojamento. Pouco antes de afirmar que "el ensayo es ciencia menos la prueba explícita”, em uma de suas mais interessantes passagens, Ortega qualifica o ensaio mais como um esforço espiritual de lucidez e atualização do que o mero pertencer a um gênero textual ou uma urdidura de formas prontas.

Con mayor razón habrá de hacerse así en ensayos de este género, donde las doctrinas, bien que convicciones científicas para el autor, no pretenden ser recibidas por el lector como verdades. Yo sólo ofrezco modi res considerandi, posibles maneras nuevas de mirar las cosas. Invito al lector a que las ensaye por sí mismo, que experimente si, en efecto, proporcionan visiones fecundas: él, pues, en virtud de su íntima y leal experiencia, probará su verdad o su error. ${ }^{4}$

O ensaio, portanto, valeria enquanto exercício criativo da faculdade de pensar, de modo que o risco do erro e o encontro com verdades parciais - e até mesmo pessoais - estariam de acordo com a elaboração de uma nova sensibilidade ${ }^{5}$, uma nova perspectiva, que estivesse para além de lugares comuns na cultura europeia de seu tempo, como o humanismo ou o cientificismo, mas que também pudesse ser útil na intenção de levar a Espanha à modernidade ocidental. Tratar-se-ia de dar as costas à realidade estabelecida para abrir novos rumos a realidades elaboradas por uma nova maneira de se relacionar com a arte, com a filosofia e com a política. Assim, propunha 
uma mudança no regime do sensível, de forma a romper com os modos tradicionais de relação com o mundo, incluindo também objetos de arte, visto que ordinariamente a arte era tomada como representadora da vida comum.

Ainda que subjetivas, internas ou parciais, Ortega pensou em realizar ideias, mesmo que irreais, dando-lhes vida concreta. É o que se nota muito bem no seu ensaio La deshumanización del Arte, de 1925, no qual afirma que não era mais época de tomar as ideias prontas como realidade. "Hacerlas vivir en su irrealidad misma es, digámoslo así, realizar lo irreal en cuanto irreal". ${ }^{6}$ Mas essa sobrevida de irrealidades pode, também, ser lida como uma nova chance àqueles elementos de uma cultura que não puderam chegar a ser tomados dentro da realidade ordinária. Mesmo em Meditaciones del Quijote, Ortega falava do ensaio especificamente como experiência de tecer elementos do espírito com motivos clássicos da cultura, se bem que não para realçar a forma, mas como uma espécie de salvação.

La "salvación" no equivale a loa ni ditirambo; puede haber en ella fuertes censuras. Lo importante es que el tema sea puesto en relación inmediata con las corrientes elementales del espíritu, con los motivos clásicos de la humana preocupación. Una vez entretejido con ellos queda transfigurado, transubstanciado, salvado. Va, en consecuencia, fluyendo bajo la tierra espiritual de estos ensayos, riscosa a veces y áspera - con rumor ensordecido, blando, como si temiera ser oída demasiado claramente -, una doctrina de amor. ${ }^{7}$

Salta aos olhos pensar o ensaio não como forma, loa, ditirambo ou qualquer outra, mas como doutrina de amor, suspensão da lei, salvação. No entender de Pedro Cerezo Galán, Ortega assume a conclusão de que "hay que sanar a España mediante la filosofía, enseñándole el gesto de meditación”. ${ }^{8}$ Um pensamento bastante arrojado, especialmente se for comparado com a definição que, em 1951, daria Adorno ao ensaio. Segundo essa definição, o ensaio não seria uma forma pronta, mas uma manifestação daquilo que é ainda antitético à ciência ou à cultura. Dando-lhe claros contornos dialéticos, o ensaio, para Adorno, seria uma chance ao desvio, ao erro ou ao opinativo que, à primeira vista, por mais irreais que soassem, poderiam fazer sentido em um nível mais elevado de compreensão. Em seu propósito, antes de chamar o ensaísmo como doutrina de salvação, Adorno o qualifica, curiosamente, como transgressão, quando afirma que "a lei formal mais profunda do ensaio é a heresia. Apenas a infração à ortodoxia do pensamento torna visível, na coisa, aquilo que a finalidade objetiva da ortodoxia procurava, secretamente, manter invisível". ${ }^{9}$

Virtude ou Heresia? Salvação ou condenação? Embora
6. ORTEGA Y GASSET, José. La deshumanización del arte y Ideas sobre la novela, 2009, p. 108.

7. Idem. Meditaciones del Quijote, 1914, p. 15-16.

8. GALÁN, Pedro Cerezo. "Meditaciones del Quijote o el estilo del héroe", 1997, p. 43.

9. ADORNO, Theodor. Notas de Literatura I, 2003, p. 45. 
10. Ibidem, p. 35.

11. ORTEGA Y GASSET, José. Meditaciones del Quijote, 1914, p. 32.

12. José Ortega y Gasset esteve na Argentina em três momentos. A primeira viagem ocorreu em 1916, a segunda em 1928. Em sua terceira estadia na Argentina, que vai de 1939 a princípios de 1942 o filósofo vinha em parte enquanto exilado pela Segunda Guerra Mundial, que já chegara à França, ao passo que a Espanha ainda estava arruinada pela Guerra Civil. Para maiores detalhes sobre o tema, Cf. ETCHECOPAR, Máximo. "Ortega y los Argentinos", 1997, p. 85-93. não haja um paralelo direto com o que Ortega y Gasset entende por ensaio, tendo em vista a clara referência à maneira hegeliana de Adorno, ambos recorrem a metáforas de cunho teológico para compreender a prática textual. E essas metáforas não condizem exatamente com provas lógicas verificáveis, ou objetivas, no sentido científico. Porém, enquanto o espanhol vê na deriva ensaística um caminho de salvação sem volta e sem chegada, Adorno entende que, mesmo enquanto heresia, ela é uma particularidade que pode fazer sentido dentro da totalidade nos descaminhos da razão.

Entretanto, se ambas as posições se distinguem na finalidade, elas se aproximam quando mencionam os sentidos do corpo humano em seus procederes ensaísticos, ressalvado o intervalo de quase quarenta anos entre a primeira teorização sobre o ensaio por Ortega em relação à de Adorno.

Como a maior parte das terminologias que sobrevivem historicamente, a palavra 'tentativa' [Versuch], na qual o ideal utópico de acertar na mosca se mescla à consciência da própria falibilidade e transitoriedade, também diz algo sobre a forma, e essa informação deve ser levada a sério justamente quando não é consequência de uma intenção programática, mas sim uma característica da intenção tateante. $^{10}$

A uma intenção programática, Adorno vê no ensaio uma intenção tateante e Ortega y Gasset, como já foi brevemente citado, "posibles maneras nuevas de mirar las cosas"11. O ensaio enquanto ato de pensamento, portanto, em duas de suas teorizações mais conhecidas, é relacionado a procedimentos eminentemente sensoriais, ora por uma faculdade visual ora por uma intenção tateante (tastenden) rumo a novos caminhos.

Contudo, antes de simplesmente se comparar duas definições programáticas bastante difundidas para evidenciar uma conceituação - ou posição - determinada sobre ensaio, também é possível traçar uma rede de conexões que estabelece um frutífero debate entre essas ideias do jovem Ortega y Gasset e alguns de seus contraditores na América Latina, com a finalidade de destacar não apenas o que Ortega disse ao mundo, mas como outros ensaístas o leram e, até mesmo, de que maneira interagiram com suas ideias e posições. Entre esses interlocutores imediatos, há duas interessantes manifestações em revistas culturais argentinas que discutem tanto a saúde quanto os sentidos, estando amplamente relacionadas com a segunda viagem do filósofo espanhol ao país sul americano durante o ano de $1928^{12}$. São os casos de Ernesto Palacio, o qual irá ensaiar uma contra-alternativa à teoria da arte desumanizada de Ortega, em 1928, na revista Criterio, da qual era um dos principais contribuintes, e também o caso de Victoria Ocampo, 
a qual publicou em 1931, no terceiro número da revista Sur, de sua direção, uma resposta na qual ela curiosamente afirma uma nova ensaística da sanidade como salvação, em uma clara defesa da inteligência. A opinião de Ocampo, como se verá, está muito próxima à de seu conterrâneo Ernesto Palacio, de sorte que ambos tentaram contra-argumentar a salvação conforme afirmava Ortega. O principal motivo de discórdia que tinham em relação a Ortega era a defesa de um propósito declaradamente intelectualista. Curiosamente também aparecem, entre suas conceituações sobre o ensaio, metáforas de órgãos sensoriais, inclusive ainda mais próximos a um sentido anatômico do que o ensaísta espanhol, de tal forma que pensaram a salvação diretamente como saúde, exercício de pensamento rumo à sanidade da imaginação. $\mathrm{E}$ assim, na medida em que são ensaios, suas teses estão sempre em confronto com desvios, de modo que essa posição espiritualista e intelectualista da parte dos contraditores argentinos de Ortega não consegue deixar que em suas respectivas escritas não surjam também elementos contraditórios a suas posições, em sintomáticas emanações da sensação.

\section{O país dos artícolas}

Tendo sido um dos fundadores da revista de vanguarda Martín Fierro, em 1924, Ernesto Palacio toma um rumo cada vez mais próximo ao nacionalismo e em consonância com as ideias dos Cursos de Cultura Católica ${ }^{13}$ nos anos 20 até o momento em que passa a contribuir regularmente para a revista Criterio ${ }^{14}$. Palacio, em geral, contribui com ensaios curtos normalmente sobre estética ou com enfoque mais específico sobre a crítica literária. Essa participação ativa não permanece por muito tempo, pois a partir de junho de 1932, quando Monsenhor Gustavo Franceschi assume a revista, dando-lhe uma direção muito mais voltada à ortodoxia religiosa, Palacio dela se afasta. Durante o tempo em que contribuiu com Criterio, destaca-se na revista o seu ensaio En el país del arte deshumanizado ${ }^{15}$, uma das publicações mais reconhecidas do periódico em seu período inicial.

O ensaio En el país del arte deshumanizado, portanto, foi escrito em concomitância com a estadia de Ortega y Gasset na Argentina, durante a qual proferiu diversas palestras, notadamente duas na Asociación Amigos del Arte, no segundo semestre de 1928. Um dos primeiros destaques a ser feitos sobre a publicação de Ernesto Palacio está no fato de que o artigo se dirige muito mais ao ensaio La deshumanización del arte de
13. Os Cursos de Cultura Católica foram agremiações para o estudo de arte, filosofia e teologia da parte de intelectuais jovens, a exemplo de Cesar Pico, Atilio dell'Oro Maini, Tomás

Casares que passaram a assumir uma religiosidade integral, e não apenas privada. Muitas vezes tiveram caráter reativo perante questões morais e até estéticas. No entanto, as discussões se ampliaram de tal modo que conseguiram reunir junto a si a participação de intelectuais não tão comprometidos pessoalmente com a religião em um espaço chamado Convivio, que reuniu personalidades como Ernesto Palacio, Jorge Luis Borges, Leopoldo Marechal ou Francisco Luis Bernárdez. Sobre o tema, Cf. ZANCA, José. "Los Cursos de Cultura Católica en los años veinte: apuntes sobre la secularización”, 2012, p. 199202.

14. Fundada e dirigida por Atilio Dell'oro Maini, em 1928, contando com poemas de Jorge Luis Borges, artigos de Eugenio d'Ors, além da presença de outros autores de outros países.

15. Dividido em seis blocos entre agosto e novembro de 1928, para melhor se adequar à editoração. 
16. Ortega y Gasset em La Rebelión de las masas escreve logo no primeiro parágrafo do texto a seguinte nota, afirmando sobre suas conferências em Buenos Aires: "En mi libro España invertebrada, publicado en 1921, en un artículo de El Sol, titulado "Masas" (1926), y en dos conferencias dadas en la Asociación de Amigos del Arte, en Buenos Aires (1928), me he ocupado del tema que el presente ensayo desarolla. Mi propósito ahora es recoger y completar lo ya dicho por mí, de manera que resulte una doctrina orgánica sobre el hecho más importante de nuestro tiempo." ORTEGA Y GASSET, José. Obras completas, 1966, p. 143. Embora essas conferências não tenham tido o texto disponibilizado e tampouco tenham sido gravadas, foram transcritas anotações dos ouvintes, as quais compõem parte do livro de ORTEGA Y GASSET, José. Meditación de nuestro tiempo: las conferéncias de Buenos Aires, 1996.

17. RANCIÈRE, Jacques. $A$ partilha do sensivel, 2009, p. 16.
Ortega, de três anos antes, do que propriamente às palestras que vinham sendo proferidas naquele momento. Nessas conferências, Ortega havia tratado de um tema que lhe interessava mais àquela data, a questão da emergência do homem-massa ao poderio social ${ }^{16}$, mais do que propriamente a defesa das novas manifestações artísticas e da necessidade de uma sensibilidade apurada e aristocrática para entendê-las, que era seu principal tema de alguns anos antes dessa segunda viagem pela América do Sul.

O país da arte desumanizada de que trata o título de Ernesto Palacio não é a Argentina de seu tempo. Tampouco é a Espanha ou qualquer outro país real. $\mathrm{O}$ país ao qual o autor se refere é o país dos artícolas, povo que vive em uma espécie de ilha utópica imaginada pelo intelectual francês André Maurois, em um ensaio publicado em livro pelo editorial da Nouvelle Revue Française, também em 1928. No país dos artícolas, todos os habitantes teriam gosto elevado para a arte e uma pequena casta de empregados, minoritária, trabalharia para manter o silêncio e a paz dos seres de espírito mais elevado. Lá só a arte sofisticada teria lugar e os sonhos seriam mais críveis do que a realidade material. Ernesto Palacio viu nessa utopia às avessas um limite intransponível, para não dizer uma contradição, na teoria da arte desumanizada do professor espanhol. Palacio entende que a separação da arte e da vida por parte de uma concepção estética na qual prevalecem novas derivas por realidades deformadas e sem que estejam adstritas a representar o mundo material, se pensadas em ampla escala, chegaria ao absurdo de uma aristocracia de massa em face de uma minoria rude, condição esta que não abarcaria nenhuma convivência social possível. Obviamente Palacio contradiz Ortega com um recurso argumentativo que se baseia em uma hipérbole que não necessariamente condiz com o que almejaria a teoria da arte desumanizada, a qual, de maneira alguma, pretendeu afirmar uma mobilização social ou difusão de um gosto estético para toda a população. Ortega meramente constata a sociedade do que hoje se entende por "entre-guerras" e sua relação com os objetos de arte. Esse intento pode ser melhor compreendido a partir do conceito de "partilha do sensível" proposto por Jacques Rancière, o qual ressalta que toda política implica em uma maneira de organizar diretamente a percepção do mundo, além de ser impossível pensar em uma sociedade que não regule suas próprias sensações. Para o autor, essa estética imanente a toda política consiste em "um recorte dos tempos e dos espaços, do visível e do invisível, da palavra e do ruído que define ao mesmo tempo o lugar e o que está em jogo na política como forma de experiência”. ${ }^{17}$ Ortega y Gasset, durante a década de 20, procurava partir dessa ordenação das sensações de que nos alerta Rancière para enfrentar o problema da massificação da 
arte. Fora de uma conceituação muito programática, tratou de pensar que uma nova relação com a arte se daria somente a partir de uma mudança direta no sensível.

É bem verdade que Ernesto Palacio, de certa maneira, também defende as novidades em manifestações artísticas e concorda com Ortega quando este diz que a arte pode ser muito mais elevada do que ficar adstrita à "representação da realidade", conforme o naturalismo, ou ainda à necessidade de provocar um gozo individual, no qual o valor estético culminaria em um louvar a si próprio, algo que seria muito próximo do pior da arte romântica. ${ }^{18}$ No entanto, Ernesto Palacio entende que os artícolas levam a pensar que o principal valor da arte não está em deformar ou não a realidade, e tampouco em representá-la ou não representá-la. Essa polaridade estaria adstrita a centralizar o problema estético na realidade sensível. "Copiar al pie de la letra la realidad, deformar deliberadamente la realidad, ambas direcciones revelan idéntico sometimiento a las apariencias sensibles, idéntica esclavitud". ${ }^{19}$ Isso porque o mais digno da arte de seu tempo, para Ernesto Palacio, seria o domínio do inteligível, mais relacionado com elementos eternos, antes do sensível, que diz respeito à efemeridade do mundo material. "Si algo caracteriza el arte nuevo - fuera de otras condiciones accidentales - es la primacía de la inteligencia sobre el sentimiento, el dominio de sí mismo, que es la esencia del espíritu clásico". ${ }^{20}$

Vale lembrar também que Palacio não estava sozinho em defesa do inteligível, afinal, o editorial de lançamento da revista Criterio, publicado apenas quatro meses antes de seu En el país del arte deshumanizado, foi intitulado como La inteligencia, além de haver quinzenalmente na revista uma coluna chamada La vida intelectual, na qual eram apresentados a seus leitores nomes como Stravinsky, Joaquín Xirau, Charlie Chaplin, José Bergamín, entre outros. Outrossim, não se pode deixar de destacar que La Vie Intellectuelle é o nome da principal revista de leigos do catolicismo na França, a qual era a principal a publicar Jacques Maritain, consistindo uma proposta editorial equiparável à de Criterio em idioma francês. Por assim dizer, não seria muito bem vista por Palacio uma doutrina que postulasse uma nova sensibilidade, uma mudança de si, a partir de uma reviravolta nas próprias circunstâncias, como era patente no pensamento de Ortega. Este, tendo sido formado em parte pelo neokantismo e em parte pela fenomenologia, teorizou que experiência de mundo e consciência não se separariam, sendo uma só e mesma circunstância. Em face dessa condição, Palacio utiliza seu trabalho ensaístico como um difusor das ideias às quais aderiu, em especial a um posicionamento intelectualista, algo que em parte estava em grande ascensão no final da década de 20, não apenas entre filósofos neoesco-
18. Entende Palacio que "Las críticas del filósofo español al romanticismo y al naturalismo del sigo XIX son, lo repetimos, perfectamente válidas. Dichas tendencias ocasionaron una perversión radical del sentido artístico, que se fue acostumbrando a platos groseros: intrigas banales condimentadas de sentimentalismo dulzón o pimienta pornográfica." PALACIO, Ernesto. "En el país del arte deshumanizado, VI”. Criterio, 1928, p. 176.

19. Ibidem, 1928, p. 269.

20. Idem. "En el país del arte deshumanizado, II". Criterio, 1928, p. 331. 


\section{Assim, as artes não} representativas durante a década de 30 ainda podiam postular um rumo de abstração dos objetos, como, aliás, já vinham fazendo Mondrian, Theo Van Doesburg, bem como Kandinsky a partir da década de 10 do século XX. Isto significa que os objetos materiais, detalhados, impuros e desajustados deveriam refletir o espírito de objetividade e racionalidade a que o homem moderno era submetido em suas vidas. Nada de adornos, repetições, enigmas, lirismo. A palavra de ordem, como já é sabido, era linha, simplicidade, exatidão e objetividade. A abstração enquanto movimento artístico visava chegar a uma conclusão muito semelhante àquela que era difundida pelo neotomismo, mesmo que por fundamentos completamente distintos, em que a abstração intelectual seria o mais real; ao passo que o mundo material seria justamente o mais abstrato.

22. KANDINSKY, Wassily. Do Espiritual na Arte e na pintura em particular, 2000.

23. PALACIO, Ernesto. "En el país del arte deshumanizado, II". Criterio, 1928, p. 331.

24. SLOTERDIJK, Peter.

Regras para o parque bumano: uma resposta à carta de Heidegger sobre o bumanismo, 2000, p. 17. lásticos, mas também da parte de artistas que se posicionavam contrariamente ao automatismo ou ao surrealismo, como os abstracionistas $^{21}$, a exemplo de Kandinsky, autor do livro Do espiritual na arte ${ }^{22}$ na década de 1910.

Ernesto Palacio afirma não concordar especialmente com a separação feita por Ortega entre realidade humana massificada e outras realidades mais elevadas, de modo que faz uma crítica declaradamente próxima ao neotomismo de Jacques Maritain, filósofo muito citado em seu ensaio. Só haveria, para Palacio, uma única realidade, a qual se manifestaria primeiramente a partir do mundo material, que seria o primeiro passo a partir do qual se poderia coligir um conteúdo inteligível, seja nas hierarquias de valores, nas causas, no bem ou no belo; mas, ainda assim, haveria uma única realidade.

Nada más arbitrario que ese rebajamiento de lo 'humano' de la 'vida', intentado por Ortega y Gasset para explicar el arte nuevo [...], nada que introduzca mayor confusión sobre el sentido de la realidad. Verdad es que ésta ofrece innumerables aspectos diversos a los diferentes ojos que la miran; pero esos aspectos no se excluyen sino que se complementan. ${ }^{23}$

Chama a atenção no trecho, para além da indignação de Palacio pela suposta separação entre o artístico e o humano, uma relevância curiosa para os olhos, os quais, ao admirar a realidade, mesmo que não fossem perfeitos ou suficientes, já seriam portas que, em conjunto, se complementariam com outras percepções. Essa metáfora visual, ao mesmo tempo em que coloca uma ênfase nos órgãos dos sentidos como imediatos do sentir e do conhecer, isto é, da sensibilidade, também poderia ser vista como um limite, já que os sentidos não dariam conta da realidade, senão de maneira parcial, humana, na falta de melhor termo.

Não se pode deixar de destacar que esse alerta contra a fragmentação, contra a perda do ideal humano, contra a decadência do gosto ou ao império das aparências, pelo simples fato de ser uma tentativa de expor teses para des-animalizar o homem, não deixa de ser uma luta que partiria do pressuposto do homem como animal. Conforme Peter Sloterdijk, "a etiqueta humanismo recorda - de forma falsamente inofensiva - a contínua batalha pelo ser humano que se produz como disputa entre tendências bestializadoras e tendências domesticadoras". 24

Entretanto, talvez o ensaio En el país del arte deshumanizado não seja tão condizente em sua forma com os conceitos nele propostos, tendo em vista que, ao final do sexto bloco do ensaio, Palacio vai ainda mais além, citando palavras de Más- 
simo Montempelli com o fim de ressaltar uma outra metáfora sensorial para falar de arte e inteligibilidade: "Au sommet de tout cela, il y aura, peut être, un Dieu, bon a prier ou avec qui lutter. [...] Resulta emocionante, en boca de un puro artista y no obstante la dubitativa expresión última, este reconocimiento de las condiciones eternas de salud para la inteligencia". ${ }^{25}$ Palacio já não demonstra exatamente uma busca de saber pela fé, pois seu principal motivo passa a ser a definição de uma saúde para a inteligência, que, paradoxalmente, se expressaria no dom, no entusiasmo ${ }^{26}$ que acometeria o artista. Ainda assim, fica expressa desta vez uma metáfora oral, para anunciar o intermédio para a arte verdadeira, que independeria da deformação ou não da realidade. Sendo de um verdadeiro artista, tanto na arte representativa quanto na arte metamórfica, o trabalho será arte por estar de acordo com pressupostos estéticos inteligíveis e objetivos que elevariam o espírito e poderiam contribuir a um saneamento da inteligência. Mas faria sentido pensar que essa inteligibilidade se manifestaria ora pelo intermédio dos olhos, ora pela boca? Seria o entusiasmo o melhor veículo para uma direção da inteligência? Para melhor evidenciar essas aporias cumpre investigar algumas semelhanças de Ernesto Palacio com Victoria Ocampo enquanto contraditora de Ortega y Gasset.

\section{"Ni ángel ni bestia"7}

Victoria Ocampo Aguirre publica, no segundo número de Sur, seu ensaio "Contestación a un epílogo de Ortega y Gasset”, na verdade um comentário tardio ao posfácio que o espanhol fez para seu texto De Francesca a Beatrice, um longo e criativo comentário sobre Dante Alighieri, no qual chega a discutir a condição da mulher, publicado pelo editorial da $R e-$ vista de Occidente, de Madrid, em 1924. Sua “Contestación” é um ensaio que irá tratar de temas estéticos muito complexos, mas que, ao mesmo tempo, apresenta uma escrita que abdica de um tom excessivamente retórico ou da precisão conceitual científica para preservar um tom intimista e afetivo, escrito em primeira pessoa, muito próximo a um tom epistolar. Neste propósito, ela demonstra inicialmente certa condescendência com as opiniões de Ortega no sentido de ter se deixado influenciar muito pelas leituras de Dante, o que lhe teria abafado seu entusiasmo pessoal e uma afirmação mais sólida de suas próprias opiniões. Tamanha gentileza também é devida ao fato de Ortega ser, já em 1931, um amigo pessoal seu, além de ter estado sempre no comitê de colaboradores de Sur, posição que
25. PALACIO, Ernesto. "En el país del arte deshumanizado, VI'. Criterio, 1928, p. 177.

26. Para tanto, Palácio faz uso de Maritain em Art e Scholastique para reforçar seu argumento acerca do dom natural do artista: "Maritain explica que 'el arte simboliza con la gracia’ y que 'entre el mundo de la poesía y el de la santidad hay uma relación de analogía. - continua Palacio

- toda doctrina que desconozca esa primacía adolece de um vicio radical que la conduce al suicidio de uma retórica. Porque retórica es, esencialmente, todo predominio de la 'voluntad de estilo' (en cualquier sentido que sea) sobre el don natural." PALACIO, Ernesto. "En el país del arte deshumanizado, III". Criterio, 1928, p. 395.

27. Palavras presentes em OCAMPO,

Victoria."Contestación a un epílogo de Ortega y Gasset”, 1931, p. 39. 
28. Segundo Judith Podlubne, o rompimento de Ortega y Gasset com Sur teria se dado em parte pelo artigo Capricho Español de julho de 1939, que qualificava como antirrepublicana a revista de ideário nacionalista Soly Luna, na qual Ortega tinha muita influência. Tal rompimento não teria, porém, ocasionado uma ruptura com sua amizade com Victoria Ocampo. PODLUBNE, Judith. Escritores de Sur: los inicios literários de José Bianco y Silvina Ocampo. 2011, p.72-73.

29. OCAMPO, Victoria. "Contestación a un epílogo de Ortega y Gasset”. Sur, 1931, p. 45.

30. Ortega y Gasset, apud. OCAMPO, Victoria.

"Contestación a un epílogo de Ortega y Gasset”. Sur, 1931, p. 33 . deixará de firmar a partir de 1939, no momento de sua terceira estadia na Argentina. ${ }^{28}$ Neste sentido, Ortega critica a aceitação do que Dante teria de menos interessante, a saber, um caráter gótico, que seria excessivamente marcado por uma busca espiritual rumo à iluminação e à transcendência, enfim, um excesso de contemplação. Mas, mesmo que confessasse certa pereza em relação a tal ponto, Victoria Ocampo vai posteriormente aos poucos defender algumas de suas posições ainda que, para isso, não se afaste de suas dúvidas e titubeações, as quais serão a maior prova de força de seu ensaio. A autora, na "Contestación”, costuma afirmar uma opinião para logo em seguida colocá-la em questão, inclusive em respeito ao seu suposto caráter demasiado gótico sugerido por Ortega. "La imaginación es la grande dispensadora de visiones erróneas. La entrada en el Paraíso está vedada a las imaginaciones indisciplinadas. ¿o piensa usted así ?"29 Mais do que se autoquestionar, ela chega ao ponto de se colocar em uma posição de escuta, devolvendo ao interlocutor um peso de autoridade. Além disso, não deixa de citar diretamente o principal argumento de Ortega, o qual havia sido escrito no posfácio para o livro De Francesca a Beatrice.

Yo pido, señora, que organicemos una nueva salud, y ésta es imposible si el cuerpo no sirve de contrapeso al alma. Una vez descubierta, la vida del alma es demasiado fácil, porque es imaginaria. Decía Nietzsche 'que es muy fácil pensar las cosas, pero muy difícil serlas'. El cuerpo significa un imperativo de realización que se presenta al espíritu. Yo diría más: el cuerpo es la realidad del espíritu. [...] La corporeidad, señora, es santa porque tiene una misión trascendente: simbolizar el espíritu. ${ }^{30}$

Trata-se de um alerta de que a mais alta ação espiritual somente se poderia dar na esfera do corpo, portanto, na pura materialidade e imanência da vida. Não no sentido de que o corpo metamorfosearia o espírito ou ainda que seja alguma espécie de alegoria da alma. Não. O corpo seria um símbolo do espírito para Ortega y Gasset, não havendo entre esses dois âmbitos uma relação de arbitrariedade, senão de uma correspondência mais direta e universal. A essa visão mais materialista e, sobretudo, vitalista de Ortega, que veria na vida material um horizonte de mudança espiritual possível, Victoria Ocampo contrapõe uma defesa de uma autonomia do transcendente e a sugestão de uma vida espiritual, que se relacionaria, mas que não se confundiria, com a vida humana material. E, entre dúvidas e tentativas, Victoria Ocampo reivindica o porquê de sua paixão por Dante sugerindo também que seu suposto espiritualismo constitui um tema de primeira importância para sua geração. Afinal, diz Ocampo, "en la Edad Media era el alma 
la que quería separarse del cuerpo y 'vivir su vida'; el cuerpo es lo que quiso negarse. Pero hoy es el cuerpo que pugna por desprenderse del alma; el alma es lo que se quiere negar" ${ }^{31}$ E, para pensar uma nova saúde à alma, seria necessário sanar a inteligência, a qual teria a função de conter as emoções e dirigir o espírito, pois "la entrada en el Paraíso está vedada a las imaginaciones indisciplinadas". 32

Tanto quanto no ensaio En el país del arte deshumanizado de Ernesto Palacio, Victoria Ocampo em sua "Contestación a un epílogo de Ortega y Gasset" apresenta uma resposta às principais teses de seu correspondente sobre a desumanização da arte. Segundo Judith Podlubne, diante da defesa de Ortega da poesia pura, ou seja, para além do humano, essa resposta se aproximaria de um moralismo.

Contra esa soberanía de las palabras liberadas de la materia humana y convertidas en pura expresión sonora, es decir, contra 'la desaparición elocutoria del poeta' que anuncia Mallarmé, Ocampo postula y defiende la unión indisociable de los aspectos formales del arte y de su finalidad moral..$^{33}$

De maneira curiosa, a diretora de Sur, tanto quanto Ernesto Palacio, propõe, pela sua atividade intelectual como ensaísta, uma saúde ao espírito ou uma salvação da imaginação quando rejeita tanto uma deformação nos padrões artísticos que tivesse por escopo a mera metamorfose instintiva - algo que seria típico da nueva sensibilidad -, assim como rejeitava uma arte meramente ideológica ou uma racionalização a ponto de afastar o homem da humanidade. Ocampo, neste propósito, traz em seu ensaio, para contrariar Ortega, um exemplo do personagem Otelo de Shakespeare como homem que perde a sanidade pela exacerbação emocional causada pelo ciúme. No outro extremo desse problema de um excesso de desvios e desumanização, Victoria Ocampo discute as escolhas dos personagens Lady Chatterley e Sir Clifford, protagonistas do romance Lady Chatterley's Lover de D. H. Lawrence, como exemplos de exacerbação da racionalidade completamente apática, por exemplo, quando o casal decide combinar suas relações conjugais com antecipação, as quais eram realizadas mecanicamente, como máquina e sem o menor resquício de humanidade.

Volviendo a los problemas de la salud y de la felicidad, creo que una humanidad que diera rienda suelta a sus instintos, tipo Otelo, y una humanidad que se intelectualizara hasta la más lúgubre sequedad, tipo Sr. Clifford, serían una humanidad profundamente atormentada. ${ }^{34}$

Ao comparar esses dois exemplos de insanidade emocio-
31. Ibidem, p. 33.

32. Ibidem, p. 12.

33. PODLUBNE, Judith.

Escritores de Sur: los inicios literarios

de José Bianco y Silvina Ocampo,

2011, p. 56-57.

34. OCAMPO, Victoria.

"Contestación a un epílogo de

Ortega y Gasset”. Sur, 1931, p. 38 . 
35. Ibidem, p. 49.

36. Sobre o tema, Cf. COMPAIGNON, Olivier.

Maritain et l'Amérique du Sud: Le modèle malgré lui, 2003.

37. OCAMPO, Victoria. "Contestación a un epílogo de Ortega y Gasset”. Sur, 1931, p. 36. nal e intelectiva, Victoria Ocampo contradiz o conceito de desumanização da arte de Ortega y Gasset bem como suas ideias de nova sensibilidade pela deformação da realidade, a partir de um argumento que recorre à hipérbole. Nestes dois exemplos, de Shakespeare e de Lawrence, os quais são trabalhados à exaustão, Victoria Ocampo descreve duas distopias para tentar mapear parcialmente duas potenciais realidades que viessem a ser deformadas e desumanizadas, mas que, ao mesmo tempo, seriam doentes na medida em que careceriam de qualquer direcionamento da inteligência. Sendo assim, a autora, tanto quanto Ernesto Palacio, demonstra uma certa inquietação com relação à desumanização da arte de Ortega y Gasset, afinal, era um imperativo de seu tempo recuperar aspectos inteligíveis da realidade contemplativa, uma luta, de modo semelhante ao que propunha Palacio, entre tendências beatificadoras e bestificadoras, que em Ocampo constituem a saída "del árbol, del animal a la línea del horizonte. De Francesca a Beatrice”. ${ }^{35}$

A partir de interlocuções sucessivas à segunda viagem de Ortega y Gasset à Argentina em 1928, pode-se notar que houve certos atritos entre suas ideias e as leituras presentes nos ensaios de Ernesto Palacio e Victoria Ocampo. À primeira vista, esse choque se deu porque a concepção de ensaio - ou salvação - enquanto saúde da parte de Ortega foi contestada em favor de uma direção mais espiritualizada, que afirmava ser o ensaio sanidade, saúde da inteligência perante o descontrole dos seus desvios. Essa leitura estava muito fundamentada, como se pôde ver, pela filosofia neotomista de autores como Jacques Maritain ou personalismo de Emanuel Mounier, autores que eram abertamente defendidos por Ernesto Palacio em seu ensaio En el país del arte deshumanizado. Da parte de Victoria Ocampo, que, embora fosse menos explícita a alguma adesão direta ao neotomismo, ela foi quem, pouco depois, deu a melhor acolhida na Argentina ao próprio Jacques Maritain, durante sua estadia entre agosto e outubro de 1936, tendo em vista que o autor foi alvo de severas críticas por parte dos membros dos Cursos de Cultura Católica, em virtude de seu posicionamento teológico pouco ortodoxo. A maior polêmica de Maritain no Rio da Prata, contudo, se deu com o jesuíta Leonardo Castellani e, curiosamente, quem assume a defesa do visitante francês em tal situação é o editorial de Sur. ${ }^{36}$ Mesmo em sua "Contestación a un epílogo de Ortega y Gasset”, de 1931, já é possível observar esse impacto do pensamento católico mais moderado em Victoria Ocampo, a qual nutre o entendimento de que "partiendo de emociones puramente personales, va hacia aquellas que son esencialmente impersonales" ${ }^{37}$, algo que está em completa conformidade, por exemplo, com o personalismo de Emanuel Mounier, que era o diretor da revista francesa Esprit, cujo problema central era pensar justamente a pessoa humana e os va- 
lores a ela ligados objetivivamente, um ponto de partida que se reconhece como transcendência da mera individualidade. Para Mounier, a pessoa é definitivamente, "movimento para um transpessoal, simultaneamente anunciado pela existência da comunhão e da valorização" ${ }^{38}$ Mas o tom intelectualista de Ocampo, no entanto, não está adstrito a uma influência católica, tendo em vista que havia outras correntes filosóficas e artísticas com intenções semelhantes. A revista Sur já contava em seus primeiros números com publicações de Walter Gropius ou Le Corbusier, por exemplo. Ambos, vale lembrar, fizeram parte do grupo Cercle et Carré $^{39}$ em Paris durante o final da década de 20 e início da de 30 ao lado de Piet Mondrian, Joaquín Torres García ou Michel Seuphor. Isto é, Sur deu destaque a artistas que participavam ativamente de uma tendência abstracionista e construtivista, em parte por inspiração da concepção de "espiritual na arte" ${ }^{40}$ de Wassily Kandinsky.

De maneira análoga ao pensamento de Ernesto Palacio de que a realidade seria uma só, apesar de se revelar fragmentada, e, contrariando em parte o que postulava a "nova sensibilidade” de Ortega, Victoria Ocampo reforça ainda em uma nota de rodapé de sua contestação a Ortega a mútua unicidade da realidade. Para tanto, cita o romancista católico François Mauriac quando este afirma que nenhum autor tem sucesso ao estabelecer um relato enquanto uma teleologia muito edificante, pois a nenhum deles estaria facultado ter uma visão onisciente do inteligível, senão apenas parcial. ${ }^{41}$ Nesse mesmo ensaio sobre o romance, Mauriac, vale ressaltar, também afirma a arte como salvação: "il faut que les puissances opposées de son être cristallisent autour de Celui qui ne change pas. Divisé contre luimême, et par là condamné à perir, le romancier ne se sauve que dans l'Unité, il ne se retrouve que quando on retrouve Dieu" ${ }^{42}$ Retomando esse tipo de raciocínio, a autora defende uma escrita que poderia partir da realidade material ou das inúmeras circunstâncias humanas a fim de realizar uma deformação dessa realidade mediante o fluir da imaginação, como seria a arte mais nova, desde que sem perder de vista essa direção sutil da inteligência rumo a uma unidade, em outros termos, conciliar a imanência com a transcendência ou agnosticismo com gnosticismo. Do contrário, qualquer posição unilateral neste sentido seria doente e sem salvação. "Pongamos que el agnóstico es miope mientras que el gnóstico es presbita. Ambos tienen la vista defectuosa"43, diz Ocampo. O problema das novas artes não estaria, por assim dizer, na resistência do homem da massa a se desligar do humano rumo a outras possibilidades estéticas, mas, muito mais, em sua visão parcial ou, metaforicamente, em seus órgãos visuais doentes, em última instância, na resistência que o próprio corpo exerce a uma compreensão integral na medida em que é falho.
38. MOUNIER, Emmanuel. O Personalismo, 2004, p. 89-

90. Além de contribuições do próprio Mounier, como se vê no artigo La inteligencia y las pasiones, publicado em um número dedicado inteiramente à inteligência em agosto de 1938 , é importante ainda destacar que o personalismo não fez seguidores apenas nos meios católicos na Argentina, tendo em vista que até mesmo em Sur seu impacto foi visto em autores pouco relacionados com a religiosidade, como Roger Caillois, o qual publicou o artigo La jerarquía de los seres em agosto de 1942, além de contribuições do próprio Mounier, como se vê no artigo La inteligencia y las pasiones, publicado em um número dedicado inteiramente à inteligência em agosto de 1938.

39. Embora a revista tenha sido publicada na forma de jornal em 1930, houve a reimpressão de facsimilar em: Cercle et Carré. Paris: Jean-Michel Place, 1994.

40. KANDINSKY, Wassily. Do Espiritual na Arte e na pintura em particular, 2000.

41. Victoria Ocampo assim traduz em seu ensaio as palavras de Mauriac: "A ningún escritor le es permitido introducir desde fuera a Dios en su relato... Un relato que quiere ser edificante nos deja la impresión de algo arreglado, montado pieza a pieza y donde Diós entra como un accesorio". OCAMPO, Victoria. "Contestación a un epílogo de Ortega y Gasset”. Sur, 1931, p. 31.

42. MAURIAC, François. Le romancier et sés personnages, 1933 , p. 160.

43. OCAMPO, Victoria. "Contestación a un epílogo de Ortega y Gasset”. Sur, 1931, p. 49 . 
44. ORTEGA Y GASSET, José.

La deshumanización del arte. Ideas

sobre la novela, 2009.

45. OCAMPO, Victoria.

"Contestación a un epílogo de

Ortega y Gasset”. Sur, 1931, p. 50.

46. ORTEGA Y GASSET, José. Meditaciones del Quijote., 1914, p. 43.
Ao invés de fazer das irrealidades novas realidades, como pressupunha Ortega em La deshumanización del arte ${ }^{44}$, mais urgente no contexto de Victoria Ocampo era a composição de um esboço de totalidade a partir dos fragmentos dessa realidade. Certamente a metáfora da doença nos olhos se associaria facilmente a uma certa ideia de intelecção, dado que o sentido da visão se projeta sempre por meio de imagens, sendo relacionável à contemplação por não chegar a ter contato direto com o objeto, como é o caso do tato ou da gustação. No entanto, logo ao final do ensaio, a autora traz outra metáfora sensorial que dirime quaisquer dúvidas acerca de um gesto de aproximação total com o mundo, pondo em xeque seu ideal intelectualista de sanar a inteligência. "Mis ojos, que tocan el firmamento, sonríen al mirar mi mano porque mi mano conoce la dulce piel de las frutas, es ciega a las estrellas", 45 A autora, portanto, caracteriza uma imersão mais direta com a realidade ao afirmar a complementaridade do tato e da gustação - a mão e a boca do artista - para a formação da realidade. Portanto, se a miopia ou a presbiopia poderiam ser dois defeitos de uma visão vertical sobre a realidade, Victoria Ocampo sugere complementar os olhos enfermos pelo tatear a pele da fruta com as mãos. Essa posição afirma a manipulação, o puro tatear, como um recurso ensaístico por excelência, uma espécie de outra face da meditação.

\section{Nem sãos, nem salvos}

As meditações e manipulações de Victoria Ocampo e Ernesto Palacio, vale frisar, em ambos os casos foram empreendidas com polidez e admiração, além de estarem inevitavelmente marcadas por Ortega. Se, em seu primeiro ensaio com maior difusão, o filósofo afirmou que "yo soy yo y mi circunstancia...”, há de se lembrar que, logo em seguida, continua a frase dizendo "y si no salvo a ella no me salvo yo"46. Os seus debatedores argentinos frisaram em seus respectivos ensaios a salvação mais do que a circunstância. Isso demonstra que, mais do que um conceito, aproveitaram de Ortega a atitude de um pensar que se queria salvação, e, portanto, suas práticas ensaísticas reformularam conceituações próprias de estética, além, é claro, de trazerem traços desses conceitos no próprio corpo do texto. Antes de experimentarem o verdadeiro e o errôneo, Ocampo e Palacio nos ensaios em questão enveredaram no dilema entre a afirmação de si e a errância. Mesclaram opiniões próprias e conceitos alheios para contradizer o ímpeto fortemente metamórfico dos ensaios de Ortega, e, nesse proceder, 
mergulharam na imanência de suas próprias imagens verbais, como se oberva nas figurações das doenças e trabalhos com os diversos sentidos, observando-se em ambos certas fugas do foco principal em defender a inteligência.

Ambos trazem à tona, nessa errância de suas respectivas manipulações, algo que remete à rápida passagem do discurso platônico Fedro (275a-e), que narra o mito da apresentação da escrita ao rei egípcio Thamous por parte do deus Theut. Após mostrar inúmeras invenções, o deus traz a escritura ao rei, o qual a repudia prontamente, qualificando-a como um phármakon, droga, isto é, um dispositivo com potencial de servir tanto enquanto remédio quanto como veneno. Platão ressalta, assim, a opinião de Sócrates de que a escritura, diferente do saber dialógico, por mais que dissesse respeito a fins benéficos, teria o perigo de ser uma repetição, tal como o mito. A escritura não ofereceria verdadeira reminiscência ou entendimento da parte daquele que lê, senão apenas uma recordação vazia de sentido na medida em que dispensa a presença do equivalente ao emissor, para ele indispensável a uma compreensão verdadeira. ${ }^{47}$ Essa mesma passagem foi o motivo para o célebre texto A farmácia de Platão de Jacques Derrida, no qual ressalta que o phármakon se dá em parte porque a escritura sempre trará ausências, que para Platão são decorrências da substituição de um emissor original ou de um pai, rei ou juiz, para dar veracidade ao jogo do logos por um mero documento passível de ser lido por qualquer um que não se insira em sua origem. Segundo Derrida,

Esta substituição [da escritura] que se opera, pois, como um puro jogo de rastros e suplementos ou, se queremos ainda, na ordem do puro significante que nenhuma realidade, nenhuma referência absolutamente exterior, nenhum significado transcendente vem bordejar, limitar, controlar; esta substituição que se poderia julgar 'louca', uma vez que se dá ao infinito no elemento da permutação lingüística de substitutos, e de substitutos de substitutos; este encadeamento desencadeado não é menos violento. ${ }^{48}$

Diante da ausência inerente à escritura, Ortega y Gasset propunha uma desrealização da noção de realidade, em outras palavras, um sepultamento da própria pátria-mãe em favor da efemeridade moderna, enfim, uma salvação pelo abandono do humano em favor da mera vida. Já Victoria Ocampo e Ernesto Palacio, em contrapartida, posicionaram-se diante da escritura em defesa da integralidade da realidade, da fusão entre nacionalismo e modernidade, uma defesa declarada do humano e da pessoa espiritual. Porém, as suas teorizações metalinguísticas sobre o ensaio também revelaram seu lado de veneno.

Em uma primeira verificação, nota-se que o raciocínio
47. Trecho da passagem de Fedro na qual Sócrates reflete sobre a importância da oralidade na escrita pela tradução de Carlos Alberto Nunes. "É que a escrita, Fedro, é muito perigosa e, nesse ponto, parecidíssima com a pintura, pois esta, em verdade, apresenta seus produtos como vivos; mas, se alguém lhe formula perguntas, cala-se cheia de dignidade. O mesmo passa com os escritos. És inclinado a pensar que conversas com seres inteligentes; mas se, com o teu desejo de aprender, os interpelares acerca do que eles mesmos dizem, só respondem de um único modo e sempre a mesma coisa." PLATÃO. Fedro, 1975, 275d-e.

48. DERRIDA, Jacques. $A$ farmácia de Platão, 2005, p. 34-35. 
comum a Ocampo e Palacio também tematizou e estabeleceu um proceder farmacológico de certa maneira, pois, enquanto Ortega ressaltava criativamente em Meditaciones del Quijote o risco de uma ciência menos a prova científica, que seria possível num modo ensaístico de pensar, Ernesto Palacio e Victoria Ocampo tomaram outro lado do phármakon, conforme anos mais tarde teorizaria Derrida, ou seja, tentaram evidenciar as aporias do mestre. Ao procurarem, por exemplo, pensar a sensibilidade aristocrática de Ortega ao extremo, seja na hipérbole da utopia do país dos artícolas ou nas distopias de Otelo ou Lady Chatterley's Lover, fizeram uma tentativa de buscar os momentos de indecidibilidade da argumentação que levaram aos conceitos de Ortega y Gasset.

Se esses procedimentos não são conforme a melhor lógica ou simplesmente não são considerados justos por terem nas hipérboles as principais armas contra o pensar de Ortega y Gasset, essas escrituras, por sua vez, não trazem ressentimento em não conterem provas analiticamente verificáveis. Isso indica que esses autores não caminhavam rumo a uma opinião neohegeliana sobre o tema, como seria posteriormente a de Adorno, que viu no ensaio uma forma predefinida para um exercício mais livre do pensamento, porém, em última instância partiu de uma ideia real ou totalidade maior. Mais do que isso, colocando-se como nova geração, mas não exatamente como filhos gratos de Ortega y Gasset, Ernesto Palacio e Victoria Ocampo realizam em seus ensaios um questionamento severo e inconsequente das decisões políticas, científicas e filosóficas de um autor que lhes era referência.

Mas o que mais vale destacar a partir desses ensaios dirigidos a Ortega y Gasset consiste no fato de que, tanto no ensaio de Ernesto Palacio quanto no de Victoria Ocampo, o procedimento de escrita não condiz exatamente com os conceitos que defendem. Se ambos são partidários de um direcionamento da inteligência de modo congruente com o neotomismo ou o personalismo em desfavor da deformação da realidade, portanto defensores de uma estética que preconizava um reforço do inteligível ante o sensível, nas entrelinhas, os dois ensaios trazem como principal recurso explicativo metáforas claras de sensações: o entusiasmo da boca do poeta que emana o divino, ao final do ensaio de Palacio, o entendimento de gnosticismo ou agnosticismo como miopia e presbiopia ou ainda a complementaridade entre tato e visão para ilustrar a metalinguagem no ensaio de Ocampo. Suas contestações não consistem, pois, na exatidão dos argumentos, mas principalmente na força de imagens verbais com forte carga sensorial, por exemplo, a reutilização dos artícolas imaginados por Maurois da parte de Palácio, até a descrição de problemas visuais por Ocampo. $\mathrm{E}$, mais do que isso, não é apenas essa descrição que condiz 
com uma escrita que responde às ausências que assombram a escrita com a sensação, mas também o fato de conseguirem aceitar muito bem essa condição. Junta-se, pois, a um direcionamento da inteligência (Psyché) um sensualismo quase erótico (Eros), um jogo imanente no texto que o condena a mais do que ser simplesmente adstrito a seus significados: na falta de melhor termo, perfazem em seus respectivos ensaios uma doutrina de amor.

Sendo assim, seja na errância do escrever, na evidenciação de paradoxos do mestre ou na emanação de imagens que contradizem a subestimação que tinham do sensível perante o inteligível, esses ensaios manifestam que essas pequenas gestualidades $^{49}$, isto é, permanências de aporias ou indecidíveis, são o que possuem de verdadeiramente singular.

Ao contestarem o sensorialismo de Ortega y Gasset como conceito, Victoria Ocampo e Ernesto Palacio não conseguem evitar a emanação de sensações em seus próprios ensaios. Tampouco chegam a vaticinar alguma transgressão ao rigor filosófico tal como Adorno futuramente definiria como heresia, identificada como o polo negativo de uma dialética cultural. Mesmo ao negar o sensorialismo do mestre em favor de um argumento intelectualista, tomam até certo ponto a concepção de ensaio como uma "ciência menos a prova científica" do colega espanhol, a ponto de propor um pensamento assistemático. E por tal razão, não podem evitar que a errância do escrever coloque em xeque o rigor na defesa de seus conceitos. Com isso, a escrita menos a prova científica de Palacio e Ocampo condena suas próprias teses de sanar da inteligência, pois, pelo alto teor de sensorialismo tátil, oral ou visual, rumam do inteligível ao sensível no tratamento do próprio corpo de seus textos. Em seus respectivos diagnósticos metalinguísticos, prescrevem no ensaiar um exercício de pensamento como se fosse um remédio manipulado, mas não oferecem mais do que uma sucessão de chazinhos caseiros quando revidam a nova sensibilidade com novas sensações, em uma lida muito mais aberta ao mundo dos sentidos que meramente da contemplação. De Beatriz a Francisca.
49. Em "O autor como gesto", Giorgio Agamben entrevê o momento poético de um texto não exatamente nos escritos ou seus significados e tampouco no autor de fato ou leitor, senão justamente na permanência da inexpressão a qual fora largada em aberto no corpo do texto. "O autor não é mais que a testemunha, o fiador da própria falta na obra em que foi jogado; e o leitor não pode deixar de soletrar o testemunho, não pode, por sua vez, deixar de transformar-se em fiador do próprio inexausto ato de jogar de não se ser suficiente." AGAMBEN, Giorgio.

Profanaçōes, 2007, p. 62-63. 


\section{Referências}

ADORNO, Theodor. Notas de Literatura I. Trad. Jorge de Almeida. São Paulo: Editora 34, 2003.

AGAMBEN, Giorgio. Profanações. Trad. Selvino José Assmann. São Paulo: Boitempo, 2007.

ALIGHIERI, Dante. A Divina Comédia - Paraíso. Trad. Ítalo Eugenio Mauro. São Paulo: Ed. 34, 1998.

Cercle et Carré. Paris: Jean-Michel Place, 1994.

COMPAIGNON, Olivier. Maritain et l'Amérique du Sud: Le modèle malgré lui. Villeneuve d'Ascq: Presses universitaires du Septentrion, 2003.

DERRIDA, Jacques. A farmácia de Platão. Trad. Rogério Costa. São Paulo: Iluminuras, 2005.

ETCHECOPAR, Máximo. “Ortega y los Argentinos”. In: AGUILAR, Ernesto et al. Ortega y la Argentina. Madrid: Fondo de Cultura Económica, 1997, p. 85-93.

GALÁN, Pedro Cerezo. "Meditaciones del Quijote o el estilo del héroe". In: AGUILAR, Ernesto et al. Ortega y la Argentina. Madrid: Fondo de Cultura Económica, 1997, p. 27-48.

KANDINSKY, Wassily. Do Espiritual na Arte e na pintura em particular. Trad. Álvaro Cabral e Antonio de Pádua Danesi. São Paulo: Martins Fontes, 2000.

MAURIAC, François. Le romancier et sés personnages. Paris: Editions R.A. Corrêa, 1933.

MOUNIER, Emmanuel. O Personalismo. Trad. Vinícius Eduardo Alves. São Paulo: Centauro, 2004.

OCAMPO, Victoria. "Contestación a un epílogo de Ortega y Gasset”. Sur. Buenos Aires, nª 2, p. 16-52, jul/dez, 1931.

ORTEGA Y GASSET, José. La deshumanización del arte. Ideas sobre la novela. Madri: Castalia, 2009. . Meditación de nuestro tiempo: las conferencias de Buenos Aires. México: Fondo de Cultura Económica, 1996. . Meditaciones del Quijote. Madri: Publicaciones de la residencia de estudiantes, 1914. 
1966.

. Obras completas. Madri: Ed. Revista de Occidente,

PALACIO, Ernesto. "En el país del arte deshumanizado, I". Criterio. Buenos Aires, p. 267-269, 30 ago. 1928.

. "En el país del arte deshumanizado, II”. Criterio.

Buenos Aires, p. 331-332, 13 set. 1928.

. "En el país del arte deshumanizado, III”. Criterio.

Buenos Aires, p. 394-395, 27 set. 1928.

. "En el país del arte deshumanizado, IV”. Criterio.

Buenos Aires, p. 45-46, 11 out. 1928.

. "En el país del arte deshumanizado, V”. Criterio.

Buenos Aires, p. 112-113, 25 out. 1928.

. "En el país del arte deshumanizado, VI”. Criterio.

Buenos Aires, p. 176-177, 8 dez. 1928.

PLATÃO. Fedro. Trad. Carlos Alberto Nunes. Belém:

Universidade Federal do Pará, 1975.

PODLUBNE, Judith. Escritores de Sur: los inicios literarios de José Bianco y Silvina Ocampo. Rosario: Beatriz Viterbo Editora; 2011.

RANCIÈRE, Jacques. A partilha do sensível. Trad. Mônica Costa Netto. São Paulo: Exo experimental, 2009.

SLOTERDIJK, Peter. Regras para o parque humano: uma resposta à carta de Heidegger sobre o humanismo. Trad. de José Oscar de Almeida Marques. São Paulo: Estação Liberdade, 2000.

ZANCA, José. "Los Cursos de Cultura Católica en los años veinte: apuntes sobre la secularización”. Prismas, revista de historia intelectual. ano 16, $\mathrm{n}^{\mathrm{a}}$ 16, p. 199-202, 2012. 
